\title{
Role of Procalcitonin in Diagnosis of Early Onset Neonatal Sepsis in a North Indian Tertiary Care Centre
}

\author{
Yogeeta Bala ${ }^{1}$, V.S. Randhawa ${ }^{1}$, Ravinder Kaur ${ }^{1}$, Arvind Saili ${ }^{2}$ and Shweta Chitkara ${ }^{\text {* }}$ \\ ${ }^{1}$ Department of Microbiology, ${ }^{2}$ Department of Neonatology, Lady Hardinge Medical College \\ and associated hospitals, New Delhi-110001, India
}

*Corresponding author

\begin{abstract}
A B S T R A C T
Neonatal sepsis is a major cause of mortality in developing countries. Accurate and quick diagnosis is difficult because of non-specific signs and symptoms, cultures being time-

Keywords

ELISA, Neonatal sepsis, Procalcitonin, ROC curve, Sensitivity, Specificity

Article Info

Accepted: 06 July 2018 Available Online: 10 August 2018 consuming and other laboratory tests lack sensitivity and specificity. This study was designed to determine the sensitivity and specificity of Procalcitonin (PCT) levels, as a diagnostic marker of early onset neonatal sepsis (EONS). 150 neonates admitted to neonatal ward with signs suggestive of neonatal sepsis were recruited into the study. Prior to commencement of antibiotics, the following investigations were carried out on neonates: blood culture, PCT and C-reactive protein (CRP) estimation. The PCT levels were measured by human procalcitonin ELISA kit. The neonates were categorized into proven, probable and clinical sepsis on the basis of laboratory findings. Predictive values and area under the ROC curve of PCT were evaluated. Out of 150 neonates, 44 had positive blood cultures. PCT level was significantly higher in neonates with proven sepsis ( $\mathrm{p}<0.05$ ). At a cut-off of $1.32 \mathrm{ng} / \mathrm{ml}$, the sensitivity and specificity, PPV and NPV of PCT in early onset neonatal sepsis was found to be $86.3 \%, 44.34 \%, 39.58 \%$ and $88.68 \%$ respectively for proven sepsis. These findings support usefulness of the PCT in diagnosis of EONS.
\end{abstract}

\section{Introduction}

Neonatal sepsis is defined as infection with evidence of systemic inflammatory process. (Ebrahim, 2011) It is a clinical syndrome characterized by systemic signs and symptoms of infection in the first month of life. (Aggarwal et al., 2001) The incidence of neonatal sepsis in the various studies has been reported to vary from $<1$ to 8.1 cases per 1000 live births. (Nizet and Klein, 2011) Neonatal sepsis is classified into early-onset neonatal sepsis (EONS $<7$ days of birth) and late-onset neonatal sepsis (LONS >7 days). (Abdel Mohsen and Ahmed Kamel, 2015) The source of infection in these two categories varies. (Nizet and Klein, 2011; Abdel Mohsen and Ahmed Kamel, 2015) Numerous factors such as; lack of antenatal care, unhygienic and unsafe delivery practices, prematurity and low birth weight contribute to the high morbidity and mortality. (Viswanathan et al., 2011) 
The diagnosis of neonatal sepsis remains a challenge. The gold standard in the diagnosis of neonatal sepsis is the isolation of pathogen from sterile sites such as blood, CSF and ascitic fluid (Labib et al., 2013). Isolation of bacteria from blood is a standard and most specific method used to diagnose neonatal sepsis. Positive cultures range from $8 \%$ to $73 \%$ in the diagnosis of potential neonatal sepsis (Tripathi and Malik, 2010). The main disadvantages of many current microbiological diagnostic methods are diagnostic delays especially with culturebased methods, suboptimal sensitivity and low specificity because of contamination; in addition, some sample types are not amenable to routine diagnostics because of their invasive nature (Tripathi and Malik, 2010; Nasir et al., 2015).

It is therefore imperative to identify other markers that can help in early diagnosis. Several serum biomarkers have been identified in the recent years that have the potential to help diagnose local and systemic infections, differentiate bacterial and fungal infections from viral syndromes or noninfectious conditions, prognosticate, and ultimately guide management, particularly of antibiotic therapy. In pediatrics, the most frequently employed biomarker to differentiate sepsis from non-infectious systemic inflammatory response syndrome (SIRS) is the C-reactive protein (CRP), which, however, is highly non-specific and has an unfavorable kinetics (Póvoa et al., 2005). Among the different molecules investigated as biomarkers of sepsis, procalcitonin (PCT) seems to be one of the most promising and most extensively studied biomarker (Pacifico et al., 2013; Rowland et al., 2015).

PCT is the precursor of calcitonin that does not demonstrate hormonal activity. It is a 116 amino acid peptide with a molecular weight of $14.5 \mathrm{kDa}$. PCT is synthesized in the C cells of the thyroid gland of healthy individuals. In healthy people, PCT levels are very low. In systemic infections, including sepsis, PCT levels are generally at least 0.5 to $2 \mathrm{ng} / \mathrm{mL}$, and often reach levels of greater than 10 $\mathrm{ng} / \mathrm{mL}$. Higher levels correlate with the greater severity of illness and poorer prognosis (Nasir et al., 2015). This makes PCT is a potential diagnostic variable for the diagnosis of bacterial infection.

Diagnosis of sepsis is however, far too complex to be reduced to a single cut off of PCT marker. However, its levels may be influenced by antimicrobial pre-treatment and non-infectious conditions like severe trauma and some autoimmune disorders (Nasir et al., 2015). In spite of these limitations; PCT has the potential to guide initiation of appropriate therapy at the earliest and reduce the emergence and spread of antibiotic resistance. There is a need to extensively evaluate and possibly consider serum PCT as an adjunctive marker to be combined to other commonly used approaches to enhance prompt and rational clinical management, before blood culture results become available (Nasir et al., 2015). The present study was aimed to assess the usefulness of serum PCT as a diagnostic marker of neonatal sepsis in our setting and its correlation with blood culture positivity.

\section{Materials and Methods}

The prospective study was conducted on neonates admitted for sepsis workup in the Neonatal ICU of Kalawati Saran Children Hospital (KSCH), New Delhi from November 2016 to March 2018. This study was conducted in the Department of Microbiology in collaboration with Department of Neonatology at LHMC, New Delhi. This study was approved by the Institutional Scientific and Ethical Committee, and written informed consents were obtained from the parents. 
A total of 150 neonates with suspected sepsis who required sepsis evaluation were considered. The inclusion criteria were neonates who were admitted to the NICU with clinical signs suggestive of sepsis.

The exclusion criteria were infants who were on antibiotics or those who had congenital anomalies. The clinical criteria for the evaluation of sepsis were: Maternal risk factors; such as fever, prolonged rupture of amniotic membrane >24hr; Neonatal history such as low birth weight ( $<2500$ grams), preterm birth (<37 weeks); Signs and symptoms of sepsis like respiratory distress, refusal to feed, convulsion, poor cry, abdominal distension, high pitched cry, irritability, apnea, and palor.

\section{Specimens and tests performed}

Before starting antibiotic therapy conventional sepsis workup was carried out in all cases including: $\mathrm{CBC}$ counts, chest $\mathrm{x}$-ray, urine culture, CSF culture and $0.5 \mathrm{~mL}$ blood sample for blood culture.

\section{Sepsis screen}

It was determined for all the neonates enrolled in the study. Positive sepsis screen was considered if any two of the following parameters were present: TLC $(<5000 / \mathrm{mm} 3)$, Immature neutrophils to TLC ratio $>0.2$, CRP positive, micro ESR $>10 \mathrm{~mm}$-first hour, Chest $\mathrm{X}$-ray (suggestive of pneumonia)

\section{Blood culture}

Blood culture was performed by automated blood culture system in all the cases. Approximately $0.5 \mathrm{ml}$ of blood was inoculated aseptically into BacT/Alert pediatric blood culture bottle. BacT/Alert bottles were incubated in BacT/Alert 3D system for 7 days. Growth obtained was identified by standard microbiological techniques. Identification of the organisms was based on cultural characteristics, results of various tests and biochemicals. Samples from other sites; as CSF, urine \& other body fluids were also processed for diagnosing neonatal sepsis, wherever necessary (Nizet and Klein, 2011).

\section{PCT assay}

Blood samples were centrifuged within 30 minutes of collection. Serum was stored at -20 degree Celsius before analysis. PCT levels were estimated by a quantitative ELISA kit (BioVendor Human Procalcitonin ELISA) in serum. The test was performed and interpreted as per the manufacturer's instructions.

According to clinical symptoms of sepsis, microbiologic and laboratory results, neonates were classified into different categories of infection as follows: (a) Group I (proven sepsis): Clinical signs and symptoms with positive blood culture. (b) Group II (probable sepsis): Clinical signs and symptoms with negative bacterial culture but with positive septic screen. (c) Group III (clinical sepsis): Clinical signs and symptoms suggestive of systemic inflammatory response (SIRS) with negative bacterial culture and negative screening test.

\section{Data collection and management}

Self-designed, pre tested proforma was used to collect demographic data, clinical presentation, associated risk factors (maternal \& neonatal), results of the laboratory investigation generated during the admission.

\section{Statistical analysis}

All the statistical data analysis was done with the help of the SPSS version 22. For qualitative and quantitative data, Chi square test and Fisher exact test were done to analyze 
the data. $p$ value less than or equal to 0.05 was considered to be statistically significant.

\section{Results and Discussion}

There were total of 150 neonates with suspicion of sepsis admitted during the study period. Majority $(84.6 \%)$ presented with respiratory distress followed by tachycardia (42\%), fever (31\%), hypothermia (22\%), lethargy (15\%). Other signs and symptoms were poor feeding, anterior fontanella bulging, anemia of prematurity, delayed cry, abdominal distension, jaundice etc. Males $(70.40 \%)$ were predominantly affected than females $(29.50 \%)$. However, this difference was statistically not significant $(\mathrm{p}=0.07)$.

Blood culture was positive in $44(29.3 \%)$ of the neonates. Of the 44 blood culture isolates obtained, 30(68\%) were gram negative bacteria followed by gram positive bacteria $14(32 \%)$. No organism was isolated from CSF or other sterile fluids. Most common organism isolated was Klebsiella spp. (36.6\%) to be followed by Staphylococcus aureus (22.7\%), Acinetobacter spp. (20.4\%), Enterococcus spp. (9\%), Escherichia coli (9\%) and Pseudomonas aeruginosa (2\%). The sepsis grading and the differences between sepsis groups are shown in Table 1. Out of 150 neonates, PCT was raised in 97 neonates $(64.6 \%)$. The mean value of PCT was significantly higher ( $p$ value $<0.0001$ ) in proven cases $(3.39 \pm 2.55) \mathrm{ng} / \mathrm{ml}$ than probable $(2.07 \pm 2.89) \mathrm{ng} / \mathrm{ml}$ and suspected cases $(1.92 \pm 2.91) \mathrm{ng} / \mathrm{ml}$. This was analysed by Kruskal Wallis test (Figure 1).

The analysis of the receiver operating characteristic (ROC) curves is depicted in figure 2 and it revealed that the best cut-off value for PCT in our study population was $1.32 \mathrm{ng} / \mathrm{ml}$. The area under the ROC curve $(95 \% \mathrm{CI})$ was $0.79(0.71-0.87)$. PCT was found to be positive in higher proportion $(86.36 \%)$ of culture positive cases and we found a highly significant association between PCT levels and cultures. $(p=0.0003)$ In this study, at a cutoff point of $1.32 \mathrm{ng} / \mathrm{ml}$, the sensitivity and specificity, PPV and NPV of PCT in early onset neonatal sepsis was found to be $86.3 \%$, $44.34 \%, 39.58 \%, 88.68 \%$ respectively for proven sepsis (Table 2).

In the present study, regarding the clinical profile of the 150 clinically suspected neonates, majority $(84.6 \%)$ presented with respiratory distress followed by tachycardia $(42 \%)$, fever $(31 \%)$, hypothermia $(22 \%)$ and lethargy (15\%). This is consistent according to the National Neonatal Perinatal Database (NNPD) 2000 report (National Neonatology Forum, 2000) and the study by Chacko et al., (2005).

The culture positivity rate in the current study was $29.3 \%$. The rate reported in other studies varied from $21 \%$ by Naher et al., (2013), $23 \%$ by Kuruvilla et al., (1998) and $18.2 \%$ by Nwadioha et al., (2010). However some studies have reported a higher rate of culture positivity (Zakariya et al., 2011; Tallur et al., 2000; Mishra et al., 2006). This difference could be because of differences in the blood volume used for culture, blood culture techniques applied, administration of antimicrobials to the mother or neonate before the collection of sample. Although bacteria are the most common agents implicated in neonatal sepsis, it can also be caused by organisms other than bacteria like viruses and fungi. Therefore, only a proportion of the blood culture from cases with clinical sepsis will be positive for pathogenic organisms.

The detection of microorganisms in the blood of a neonate with sepsis has a great therapeutic and prognostic significance. In view of this, timely detection of blood borne pathogens is one of the most important functions of a microbiology laboratory. 
Table.1 Sepsis grading and characteristics of neonatal sepsis $(n=150)$

\begin{tabular}{|c|c|c|c|c|}
\hline Characteristics & Total $(n=150)$ & $\begin{array}{l}\text { Group I }(\mathrm{n}=44) \\
\text { Proven sepsis }\end{array}$ & $\begin{array}{l}\text { Group II (n=62) } \\
\text { Probable sepsis }\end{array}$ & $\begin{array}{l}\text { Group III }(n=44) \\
\text { Clinical sepsis }\end{array}$ \\
\hline $\begin{array}{l}\text { Age } \\
<3 \text { days } \\
>3 \text { days } \\
\end{array}$ & $\begin{array}{l}128(85.3 \%) \\
22(14.6 \%)\end{array}$ & $\begin{array}{l}33(25.7 \%) \\
11(50 \%)\end{array}$ & $\begin{array}{l}55(43 \%) \\
7(31.8 \%)\end{array}$ & $\begin{array}{l}40(31.3 \%) \\
4(18.2 \%)\end{array}$ \\
\hline $\begin{array}{l}\text { EGA* } \\
\text { Preterm } \\
\text { Term }\end{array}$ & $\begin{array}{l}119(79.3 \%) \\
31(20.7 \%)\end{array}$ & $\begin{array}{l}38(32 \%) \\
6(19.3 \%)\end{array}$ & $\begin{array}{l}54(45.3 \%) \\
8(25.8 \%)\end{array}$ & $\begin{array}{l}27(22.7 \%) \\
17(54.9 \%)\end{array}$ \\
\hline $\begin{array}{l}\text { Birth weight/grams } \\
\text { Low } \\
\text { Normal }\end{array}$ & $\begin{array}{l}127(84.6 \%) \\
23(15.4 \%)\end{array}$ & $\begin{array}{l}41(32.2 \%) \\
3(13 \%)\end{array}$ & $\begin{array}{l}53(41.7 \%) \\
9(39.1 \%)\end{array}$ & $\begin{array}{l}33(26 \%) \\
11(47.9 \%)\end{array}$ \\
\hline
\end{tabular}

*EGA: Estimated gestational age

Table.2 Sensitivity and specificity of procalcitonin levels as a diagnostic marker of early onset neonatal sepsis

\begin{tabular}{|l|l|l|l|l|l|l|}
\hline $\begin{array}{l}\text { Blood } \\
\text { Culture }\end{array}$ & $\begin{array}{l}\text { PCT } \\
>1.32 \\
\text { ng/ml }\end{array}$ & $\begin{array}{l}\text { PCT } \\
<1.32 \\
\text { ng/ml }\end{array}$ & Sensitivity (95\% CI) & Specificity(95\% CI) & PPV & NPV \\
\hline Positive & 38 & 6 & $86.36 \%$ & $\begin{array}{l}44.34 \% \\
(31.60 \%-51.76 \%)\end{array}$ & $39.58 \%$ & $88.68 \%$ \\
\hline Negative & 59 & 47 & $(69.93 \%-93.36 \%)$ & &
\end{tabular}

*CI= Confidence Interval, PPV= Positive Predictive Value, NPV= Negative Predictive Value

Fig.1 Procalcitonin profile in all cases included in the study $(n=150)$

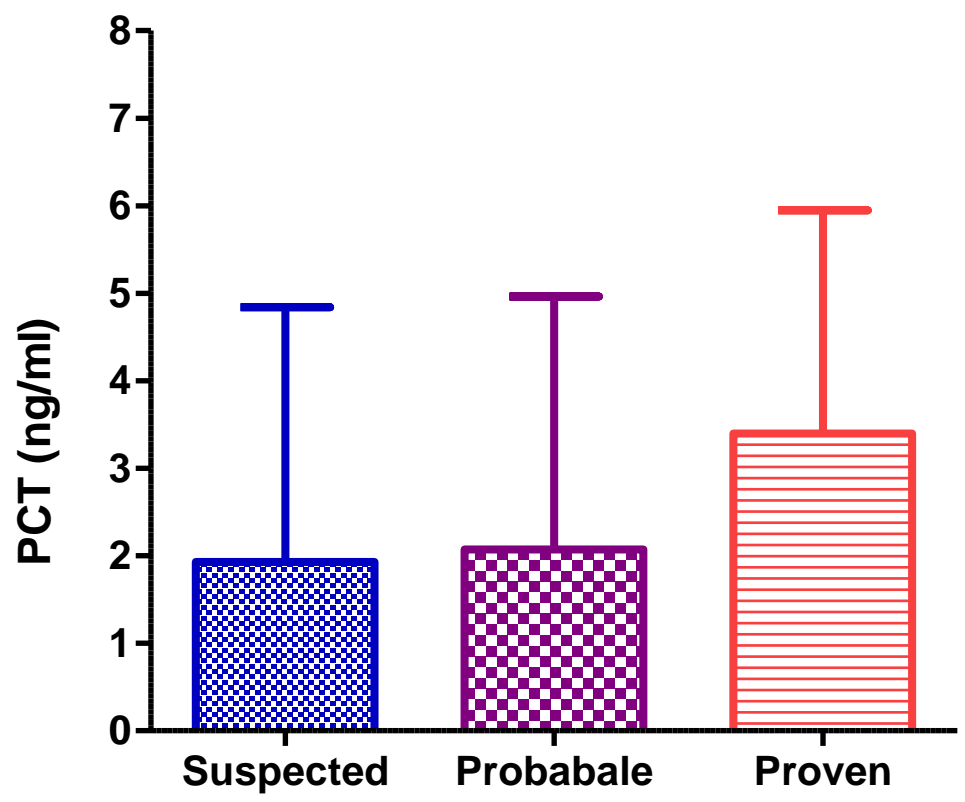


Fig.2 Figure of ROC curve

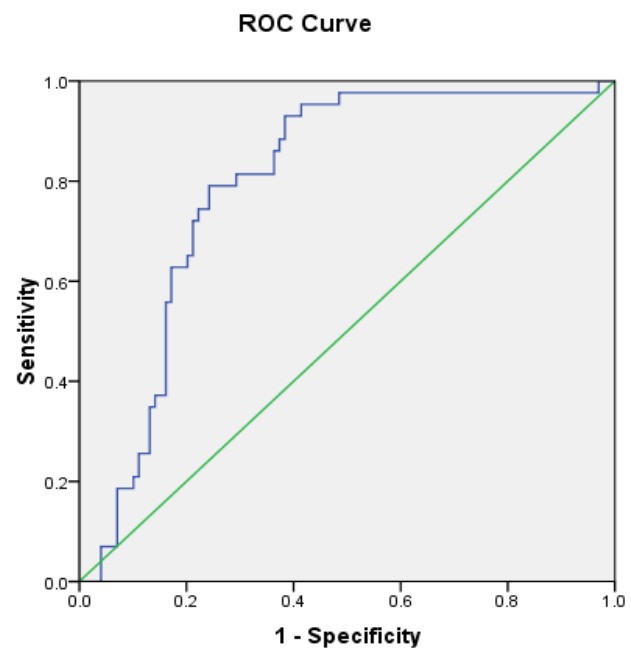

In the current study, using BacT/ Alert system, majority $(72 \%)$ of clinically significant pathogens were recovered within the first 12 hours of incubation and all pathogens were recovered within 24 hours. These findings are similar to those of Gopi et al., (2014) and Pal et al., (2009) using the BACTEC system.

In the present study gram negative organisms $(68 \%)$ were more common than gram positive organisms (32\%) as etiological agent which is in accordance with many other studies (Viswanathan et al., 2011; Kuruvilla et al., 1998; Nwadioha et al., 2010; Zakariya et al., 2011; Tallur et al., 2000).

Assicot et al., (1993) were the first to describe procalcitonin as a potential biomarker for sepsis and infection in 1993, and since then many studies on PCT have been carried out. The cut-off of PCT used in our study was determined by the ROC curve. The range of physiological concentrations in neonates is wide and depends on the day of life (Chiesa et al., 2000). At the same time, the sensitivity and specificity for the diagnosis of infection, depend on the subjectively presumed cut-off point (Chiesa et al., 2000; Ugarte et al., 1999). In this study, at a cut-off point of 1.32 $\mathrm{ng} / \mathrm{ml}$, the sensitivity and specificity, PPV and NPV of PCT in early onset neonatal sepsis was found to be $86.3 \%, 44.34 \%, 39.58 \%$, $88.68 \%$ respectively for proven sepsis. This high sensitivity and NPV of PCT is consistent with the studies of Ballot et al., (2004) in South Africa and Sucilathangam et al., (2012) in India and Zahedpasha et al., (2009) in Iran. Thus it can be inferred that PCT assay is an effective tool to help to diagnose sepsis.

PCT values in cases of neonatal sepsis with gram negative organisms were higher (mean value $3.633 \mathrm{ng} / \mathrm{ml}$ ) than those with gram positive organisms (mean value $2.941 \mathrm{ng} / \mathrm{ml}$ ). This finding is similar to Yu et al., (2015).

Cases with a very high PCT value suggest more likelihood of gram negative bacterial blood infection. Yu et al., (2015) this may be explained by the fact that gram-negative bacteremia induces a greater inflammatory response than gram-positive bacteremia and hence the higher PCT levels in gram-negative bacteremia (Reinhart et al., 2012; Brodská et al., 2013). 
In the present study, the specificity of PCT was $64.5 \%$ at cut-off of $>1.32 \mathrm{ng} / \mathrm{ml}$. In the study by Kordek et al., (2008), the cut-off point for PCT in cord blood was $1.22 \mathrm{ng} / \mathrm{mL}$, sensitivity of $80.43 \%$, specificity of $71.67 \%$, PPV of $35.24 \%$ and NPV of $95.03 \%$. Chan YL et al., (2004) reported sensitivity of $69.5 \%$ and specificity of $64.5 \%$ for PCT, using a cutoff of $0.6 \mathrm{ng} / \mathrm{ml}$. Janota et al., (2001) indicated the sensitivity and specificity of $75 \%$ and $59 \%$ for procalcitonin respectively, at a cutoff of $2 \mathrm{ng} / \mathrm{ml}$.

The high proportion of false positive results (and therefore low specificity) could be partially explained by the normal progressive rise of PCT during the first 48 hours of life for both term and preterm neonates. The physiological peak of serum PCT concentrations in healthy neonates has been previously reported (Chiesa et al.,) and increased PCT concentrations have also been found in neonates with very low probability of infection (Monneret et al., 1997). This postnatal surge of PCT might be attributed to direct stress on the baby during the perinatal period. The normal birth process and the extrauterine adaptation stimulates an acute phase reaction in the newborn infant with a release of C-reactive protein (CRP), interleukin-6 (IL-6), and serum amyloid A (Chiesa et al., 2003).

Another reason for low specificity in our study is that, majority of neonates presented with respiratory distress $(84.6 \%)$, this is also consistent with previous studies, in which higher concentrations of PCT observed in uninfected neonates with respiratory disorders and hemodynamic failure compared with asymptomatic neonates (Lapillonne et al., 1998). Monneret et al., (1997) demonstrated elevated PCT values in uninfected newborns who presented with respiratory distress syndrome (RDS) and suggested that hypoxemia could be responsible for these increased PCT values, providing further support for the hypothesis of pulmonary PCT synthesis. (Monneret et al., 1997)

In neonates, an elevated PCT level may help in predicting sepsis; furthermore, low PCT levels were helpful in ruling out sepsis as a diagnosis. In our study, NPV was $88.68 \%$. The good negative predictive value found suggested that PCT can be tested rapidly and is a highly discriminating means to rule out bacteremia. Therefore, PCT assessment could help physicians limit the number of unnecessary prescriptions for antibiotics.

Rapid diagnosis by using Procalcitonin gives a reasonable degree of accuracy in early diagnosis of neonatal sepsis which will also help to initiate early antibiotic therapy. Limitations of our study were that it was single centric study, small sample size and serial sampling was not possible.

\section{Acknowledgments}

\section{Declaration of funding}

The authors declare no financial support.

\section{Ethical approval}

The study was conducted after obtaining ethical approval from the institutional ethical committee.

\section{Conflicts of interest}

The authors declare no personal or financial conflict of interest.

\section{References}

Abdel Mohsen AH, and Ahmed Kamel B. Predictive values for procalcitonin in the diagnosis of neonatal sepsis. Electron Physician. 2015 Aug 10; (4): 1190-1195. 
Aggarwal R, Sarkar N, Deorari AK, Paul VK. Sepsis in the newborn. Indian $\mathrm{J}$ Pediatr. 2001; 68(12): 1143-1147.

Assicot M, Bohuon C, Gendrel D, Raymond J, Carsin H, Guilbaud J. High serum procalcitonin concentrations in patients with sepsis and infection. The Lancet. 1993; 341(8844): 515-518.

Ballot DE, Perovic O, Galpin J, Cooper PA. Serum procalcitonin as an early marker of neonatal sepsis. South Afr Med J SuidAfr Tydskr Vir Geneeskd. 2004 Oct; 94(10): 851-4.

Brodská H, Malíčková K, Adámková V, Benáková H, Št’astná MM, Zima T. Significantly higher procalcitonin levels could differentiate Gram-negative sepsis from Gram-positive and fungal sepsis. Clin Exp Med. 2013 Aug; 13(3): 165-70.

Chacko B, Sohi I. Early onset neonatal sepsis. Indian J Pediatr. 2005; 72(1): 23.

Chan Y-L, Tseng C-P, Tsay P-K, Chang S-S, Chiu T-F, Chen J-C. Procalcitonin as a marker of bacterial infection in the emergency department: an observational study. Crit Care Lond Engl. 2004 Feb; 8(1): R12-20.

Chiesa C, Pacifico L, Rossi N, Panero A, Matrunola M, Mancuso G. Procalcitonin as a marker of nosocomial infections in the neonatal intensive care unit. Intensive Care Med. 2000 Feb; 26(2): S175-7.

Chiesa C, Panero A, Rossi N, Stegagno M, Giusti MD, Osborn JF, et al., Reliability of Procalcitonin Concentrations for the Diagnosis of Sepsis in Critically Ill Neonates. : 9.

Chiesa C, Pellegrini G, Panero A, Osborn JF, Signore F, Assumma M, et al., C-reactive protein, interleukin-6, and procalcitonin in the immediate postnatal period: influence of illness severity, risk status, antenatal and perinatal complications, and infection. Clin Chem. 2003 Jan; 49(1): 60-8.

Ebrahim GJ. Sepsis, septic shock and the systemic inflammatory response syndrome. J Trop Pediatr. 2011 Apr 1; 57(2): 77-9.
Gopi A, Arun KR, Harindranath D. Evaluation of time to positivity in detection of microorganism using BACTEC [TM] 9050 in a tertiary care hospital over a period of one year. J Evol Med Dent Sci. 2014; 3(64): 13999-14006.

Janota J, Stranak Z, Belohlavkova S, Mudra K, Simak J. Postnatal increase of procalcitonin in premature newborns is enhanced by chorioamnionitis and neonatal sepsis. Eur J Clin Invest. 2001 Nov; 31(11): 978-83.

Kordek A, Hałasa M, Podraza W. Early detection of an early onset infection in the neonate based on measurements of procalcitonin and $\mathrm{C}$-reactive protein concentrations in cord blood. Clin Chem Lab Med. 2008; 46(8): 1143-1148.

Kuruvilla KA, Pillai S, Jesudason M, Jana AK. Bacterial profile of sepsis in a neonatal unit in south India. Indian Pediatr. 1998; 35(9): 851-8.

Labib AZ, Mahmoud AB, Eissa N, El Gendy FM, Soliman MA, Aly AA. Early diagnosis of neonatal sepsis: a molecular approach and detection of diagnostic markers versus conventional blood culture. Int J Microbiol Res. 2013; 4: 7785.

Lapillonne A, Basson E, Monneret G, Bienvenu $J$, Salle BL. Lack of specificity of procalcitonin for sepsis diagnosis in premature infants. The Lancet. 1998 Apr; 351(9110): 1211-2.

Mishra UK, Jacobs SE, Doyle LW, Garland SM. Newer approaches to the diagnosis of early onset neonatal sepsis. Arch Dis Child-Fetal Neonatal Ed. 2006; 91(3): F208-F212.

Monneret $\mathrm{G}$, Labaune J, Isaac C, Bienvenu F, Putet G, Bienvenu J. Procalcitonin and Creactive protein levels in neonatal infections. Acta Paediatr. 1997 Feb; 86(2): 209-12.

Naher HS, Khamael AB. Neonatal sepsis; the bacterial causes and the risk factors. Int Res J Med Sci. 2013; 1(6): 19-22.

Nasir I, Mele H, Babayo A, Yahaya F. Serum Procalcitonin Assay for Investigations 
and Clinical Management of Neonatal Sepsis: A Review. J Pediatr Infect Dis. 2015 Jul 3; 10(01): 003-11.

Nizet V, and Klein JO. CHAPTER 6 - Bacterial Sepsis and Meningitis. In: Infectious Diseases of the Fetus and Newborn (Seventh Edition). Philadelphia: W.B. Saunders; 2011. p. 222-75.

Nwadioha SI, Nwokedi EOP, Kashibu E, Odimayo MS, Okwori EE. A review of bacterial isolates in blood cultures of children with suspected septicemia in a Nigerian tertiary Hospital. Afr J Microbiol Res. 2010; 4(4): 222-225.

Pacifico L, Osborn JF, Natale F, Ferraro F, De Curtis M, Chiesa C. Procalcitonin in pediatrics. Adv Clin Chem. 2013; 59: 203-63.

Pal N, Sharma R, Rishi S, Vyas L. Optimum time to detection of bacteria and yeast species with BACTEC 9120 culture system from blood and sterile body fluids. J Lab Physicians. 2009; 1(2): 69.

Póvoa P, Coelho L, Almeida E, Fernandes A, Mealha R, Moreira $\mathrm{P}$, et al., C-reactive protein as a marker of infection in critically ill patients. Clin Microbiol Infect Off Publ Eur Soc Clin Microbiol Infect Dis. 2005 Feb; 11(2): 101-8.

Reinhart K, Bauer M, Riedemann NC, Hartog CS. New approaches to sepsis: molecular diagnostics and biomarkers. Clin Microbiol Rev. 2012 Oct; 25(4): 609-34.

Report of the National Neonatal Perinatal Database (National Neonatology Forum) 2000.

Rowland T, Hilliard H, Barlow G. Procalcitonin: potential role in diagnosis and management of sepsis. Adv Clin Chem. 2015; 68: 71-86.
Sucilathangam G, Amuthavalli K, Velvizhi G, Ashihabegum MA, Jeyamurugan $\mathrm{T}$, Palaniappan N. Early diagnostic markers for neonatal sepsis: comparing procalcitonin (PCT) and C-reactive protein (CRP). J Clin Diagn Res. 2012; 6(4): 627-631.

Tallur SS, Kasturi AV, Nadgir SD, Krishna BVS. Clinico-bacteriological study of neonatal septicemia in Hubli. Indian $\mathbf{J}$ Pediatr. 2000; 67(3): 169-174.

Tripathi S, and Malik GK. Neonatal Sepsis: past, present and future; a review article. Internet $\mathrm{J}$ Med Update-EJOURNAL. 2010; 5(2).

Ugarte H, Silva E, Mercan D, De Mendonça A, Vincent JL. Procalcitonin used as a marker of infection in the intensive care unit. Crit Care Med. 1999 Mar; 27(3): 498-504.

Viswanathan R, Singh AK, Mukherjee S, Mukherjee R, Das P, Basu S. Aetiology and antimicrobial resistance of neonatal sepsis at a tertiary care centre in eastern India: a 3 year study. Indian J Pediatr. 2011; 78(4): 409-412.

Yu Y, Li X-X, Jiang L-X, Du M, Liu Z-G, Cen $\mathrm{Z}-\mathrm{R}$, et al., Procalcitonin levels in patients with positive blood culture, positive body fluid culture, sepsis, and severe sepsis: a cross-sectional study. Infect Dis. 2015 Sep 4; 48: 63-9.

Zahedpasha Y, Ahmadpour M, Haghshenas M. Procalcitonin as a Marker of Neonatal Sepsis. Iran J Pediatr. 2009; 19(2): 6.

Zakariya BP, Bhat V, Harish BN, Babu TA, Joseph NM. Neonatal sepsis in a tertiary care hospital in South India: bacteriological profile and antibiotic sensitivity pattern. Indian J Pediatr. 2011; 78(4): 413-417.

\section{How to cite this article:}

Yogeeta Bala, V.S. Randhawa, Ravinder Kaur, Arvind Saili and Shweta Chitkara. 2018. Role of Procalcitonin in Diagnosis of Early Onset Neonatal Sepsis in a North Indian Tertiary Care Centre. Int.J.Curr.Microbiol.App.Sci. 7(08): 490-498. doi: https://doi.org/10.20546/ijcmas.2018.708.054 